\title{
El Derecho desde la Antropología: Etnografía y Derecho consuetudinario en Madagascar
}

\author{
The Law after Anthropology: \\ Ethnography and Costumary Law in Madagascar
}

\author{
Mariona ROSÉS TUBAU \\ Universitat de Barcelona \\ mionart@hotmail.com
}

Recibido: 25 de julio de 2014

Aceptado: 11 de mayo de 2015

\section{Resumen}

Este artículo pretende contribuir a poner de manifiesto la relación entre el Derecho y la Antropología prestando una atención particular al derecho consuetudinario. Tomamos el caso concreto de Madagascar con el propósito de analizar la etnografía como fuente de derecho, incidiendo en su relación con el derecho constitucional malgache, a partir de los conflictos que generan los robos de cebúes en el ámbito local y rural de las comunidades malgaches.

Palabras clave: Costumbre jurídica; Normativa jurídica de Madagascar; Peculiaridades jurídicas consuetudinarias; Etnografía.

\begin{abstract}
This article aims to unveil the links between Law and Anthropology, paying special attention to the Customary Law. I will focus on the particular case study of Madagascar in order to analyze the ethnography as a source of Law, going further in its relations with Malagasy Constitutional Law, and taking as a reference the conflicts arising from Zebu rustling in the rural communities of Madagascar.
\end{abstract}

Keywords: Costumary Law; Madagascar Legal System; Ethnography.

Referencia normalizada: Rosés Tubau, M. (2015) Derechos y pueblos indígenas: avances objetivos, debilidades subjetivas, en Revista de Antropología Social 24, 177-188.

SUMARIO: 1. Introducción. 2. El dina: entre la costumbre local y la ley estatal. 3. De la ley abstracta a la práctica jurídica en la región de la haute matsiatra: el caso del dina regional y los robos de cebúes. 4. Reflexiones finales. 5. Referencias bibliográficas.

\section{Introducción}

Con el propósito de poner de manifiesto la relación de igualdad entre Derecho y Antropología, nos planteamos analizar las fuentes antropológicas como fuente de 
derecho. Nuestro objetivo particular es el de esclarecer la articulación de la etnografía con el derecho constitucional y para ello tomaremos como referencia el caso de Madagascar.

Este caso concreto nos permitirá llevar a cabo un análisis sobre la interrelación que se produce entre la etnografía y el derecho en el ámbito consuetudinario, a partir del recorrido de ida y vuelta que tiene lugar cuando el Estado malgache se apropia de recursos propios del derecho consuetudinario y los incluye - transformadosen el derecho constitucional. Asimismo veremos también como dicho proceso de apropiación y reformulación da lugar a una contrapartida: La entrada del derecho positivo en el derecho consuetudinario.

Para alcanzar nuestro reto recurrimos al dina, un recurso jurídico propio del derecho consuetudinario malgache, que el Estado de Madagascar transforma en recurso jurídico del derecho constitucional. La convivencia de dos dina distintos en el ámbito local de las comunidades malgaches da lugar a múltiples casos de conflicto entre ambas culturas jurídicas - la civil y penal y la costumbre jurídica - que salen a la luz en los problemas concretos, entre los cuales destacan los robos de cebúes, a los que prestaremos una atención particular.

En la República Democrática de Madagascar identificamos el derecho constitucional, con sus leyes civiles y penales, y permanentemente paralela a ellas la costumbre jurídica. Se trata de dos tipos de justicia que beben de fuentes muy distintas pero que, a lo largo de la historia del país, han ido encontrándose con más o menos conflicto entre ellas.

Aunque anteriormente ya existieron casos precursores, el Estado malgache comienza a tomar la costumbre y los recursos jurídicos de ésta de manera sistemática especialmente en los años 1980. A partir de esta década, cuando los robos de cebúes presentan un auge numérico considerable y una crudeza inédita hasta el momento, el Estado se ve abocado a buscar nuevos recursos jurídicos distintos a los ya aplicados para combatir esta práctica y los conflictos que se derivan de ella. El dina se erige como el recurso jurídico en el que se ampara el Estado. No obstante, los dina locales - "originales" - siguen vigentes, paralelos a los dina estatales. Son el recurso jurídico en el que se respaldan las comunidades, la ley y el procedimiento aplicados para los casos de conflicto en el marco local.

\section{El dina: entre la costumbre local y la ley estatal}

Para comprender el entramado de apropiaciones y reapropiaciones de recursos jurídicos que nos proponemos discernir en este artículo partiremos de la siguiente premisa: Los dina tienen una historia y, del mismo modo, la relación dina-Estado también la tiene (Rosés, 2013).

Originalmente el dina se comprende como un acuerdo entre los miembros de una o varias comunidades. La necesidad de su creación viene dada para responder a las carencias de una comunidad o un grupo de comunidades, o bien para afrontar un contratiempo social con el fin de evitar su repetición. Se formaliza en un acto ritual, normalmente un juramento, en el que se pronuncian las imprecaciones y sanciones que van a recibir aquellos que desobedezcan las reglas del dina adoptado. 
La función de este acto ritual es la de consagrar el dina públicamente con el fin de que los juramentos efectuados ejerzan su fuerza coercitiva y con ello se respeten las reglas del dina (Njara, 1993). De este modo, los dina articulan cuatro factores que los caracterizan: En primer lugar, el problema para el que se busca una solución. En segundo lugar, los términos del acuerdo y las personas que lo llevan a cabo. En tercer lugar, las sanciones que deben aplicarse en caso de infracción en forma de maldiciones o multas. Y por último, el ritual en el que se adopta el dina durante el cual se pronuncia el juramento. No obstante hay que tener en cuenta que este significado primigenio ha cambiado y se modificado a lo largo de la historia política de Madagascar (Razanabahiny, 1995). Unos cambios que tienen mucho que ver con la relación que se establece entre los dina y el Estado o el poder central en las distintas épocas históricas.

En este artículo queremos ocuparnos del período postcolonial más reciente, cuando bajo el manto de la ley 2001-004 ${ }^{1}$ el Estado homogeneiza el dina en un modelo legalizado de acuerdo con las leyes estatales. Esta iniciativa viene impulsada, como decíamos anteriormente, por el auge de los robos de cebúes y los cambios sustanciales en su forma. Ante la magnitud de esta problemática, el Estado malgache ensaya varios tipos de dina estatales durante las décadas de los ochenta y los noventa hasta dar, a finales de los años 2000, con su última variante: los dina regionales.

La creación de los dina regionales responde a unos objetivos estatales concretos. El Estado malgache desea remplazar no únicamente aquellos dina locales creados para el mismo efecto, sino también los dina precedentes de creación estatal, como son los dina de distrito o de provincia, vigentes hasta los años 2000 y característicos de toda la década de los noventa. El propósito deseado no es otro que homogeneizar las reglas en una misma Región. De aquí la creación de los llamados dina regionales para satisfacer el objetivo subyacente del Estado: Asumir una responsabilidad colectiva para combatir los robos de cebúes legalmente. Una responsabilidad colectiva, inherente en los dina como recurso jurídico, que se reparte entre las comunidades, las asociaciones de la sociedad civil, los representantes del Estado y las fuerzas del orden, comprometiéndose a aplicar las reglas del dina regional. El Estado pretende evitar la existencia de un poder paralelo al suyo y legitimar políticamente la ley referente a los robos de cebúes. Para ello debe hacer presente la costumbre jurídica, ya legitimada de facto por las comunidades.

Llegados a este punto es necesario cuestionarnos en qué lugar se encuentra la costumbre jurídica en este entramado de justicia estatal.

A pesar de que la costumbre jurídica pasa por varias etapas de invisibilización - principalmente durante la colonización francesa- ésta pervive en el seno de las comunidades locales, especialmente en el ámbito rural. Debemos recordar brevemente que en el contexto de la primera época postcolonial, en el nuevo Madagascar independiente se plantea unificar el derecho malgache tomando tanto las costumbres

${ }^{1}$ Ley 2001-044 del 25 de octubre de 2001 sobre la reglamentación general de los dina en materia de seguridad pública, Journal Oficiel n²746 del 19 de noviembre de 2001, p.3047. 
locales como el legado del derecho colonial francés. A partir de este momento, el lugar de la costumbre jurídica será variable: El derecho constitucional acepta algunas costumbres y las incluye en su código civil pero otras las niega. Aunque la forma más común de presentar la costumbre jurídica es codificada por la ley, este no es el caso para los robos de cebúes, dado que las costumbres locales para su regulación quedan terminantemente prohibidas hasta día de hoy.

Aún así, cuando tiene lugar la creación de los dina regionales, a mediados de los años 2000, aquellos dina locales que se han creado y adoptado con la finalidad de combatir los robos de cebúes siguen vigentes. Ilegalmente, y a pesar de contar con un recurso jurídico aparentemente idéntico y además legalizado, se siguen aplicando sus reglas y el procedimiento acordado para resolver los conflictos que se derivan de los robos de cebúes entre los miembros de las comunidades que han creado estos dina.

La razón de esta circunstancia no radica únicamente en la cuestión de la ilegalidad, sino que también encuentra su explicación en aspectos relacionados con el parentesco, la alianza y la costumbre común que comparten los miembros que conforman dichas comunidades. Por ello, en este momento concreto, debemos subrayar la posición de la costumbre así como su aceptación por las comunidades malgaches, especialmente en el ámbito rural.

Los malgaches viven sus relaciones sociales diferenciando aquellos con los que les une una relación de parentesco o alianza de los que no. Con los que conforman su red de parentesco y alianza deben cumplir unas obligaciones y pueden exigir unos derechos, como si de una ley se tratara, que hacen referencia a la solidaridad, la ayuda mutua y la cohesión social. El carácter obligatorio de la costumbre se pone en evidencia mediante reglas y prácticas que se asumen para atender la cohesión y solidaridad deseadas, así como para evitar la exclusión social (Rosés, 2013). De esta forma se ejerce un control social casi invisiblemente (Bloch, 1971) y las relaciones en la costumbre se regulan de forma natural.

Aunque deban tenerse en cuenta las omisiones y manifestaciones contrarias, que también tienen lugar, hacía las reglas que promulga esta costumbre jurídica local, lo cierto es que se generan mecanismos y decisiones que permiten gestionar los conflictos en el ámbito local, puesto que las formas de la costumbre, de los dina locales, apuntan hacia una responsabilidad solidaria (Terradas, 2008) que actúa en beneficio del colectivo. La coerción que ejercen los vínculos de parentesco y las relaciones de poder en el marco local así como la necesaria obediencia a la estructura tradicional permite eludir el conflicto en buena parte de los casos.

No obstante, la forma de estos dina locales difiere de su versión original de antaño adaptándose a un nuevo contexto. En este nuevo contexto, la presencia de un dina legal de aplicación obligada para aquellos casos de conflicto derivados de los robos de cebúes, el dina regional, obliga a las comunidades a reinterpretar su propio derecho consuetudinario, sin perder su esencia pero ajustándose a la realidad presente. El dina local como costumbre jurídica se observa como un elemento de adecuación a la realidad cambiante al mismo tiempo que es un recuerdo imperioso de la obediencia a los orígenes (Assier-Andrieu, 2001). Igualmente se debe interpretar su permanencia como una respuesta a las carencias y ausencias del Estado. 


\section{De la ley abstracta a la práctica jurídica en la región de la haute matsia- tra: el caso del dina regional y los robos de cebúes}

Si nos adentramos en la Región de la Haute Matsiatra, la etnografía nos permitirá analizar el entramado jurídico actual. Tomando los casos de conflicto surgidos a razón de los robos de cebúes veremos de que manera se visibiliza la ley en el contexto local y como lo hace la costumbre. No de forma independiente, sino retroalimentándose mutuamente.

En esta región interior de Madagascar, cuyos recursos económicos son fundamentalmente la agricultura y la ganadería del cebú, en el año 2007 se implanta el dina de la Región de la Haute Matsiatra. Este dina se convierte en el texto de ley de referencia para las comunidades de dicha Región. Aprobado el 20 de septiembre de 2007, el dina regional es resultado de unas iniciativas estatales que empiezan a emprenderse en el año 2004, cuando el Estado de Madagascar inicia un proyecto gubernamental de descentralización. Su objetivo es el de transferir mayor competencia a las Comunas para que éstas sean la base del desarrollo del país. Con el propósito de conseguir un desarrollo sostenible y rápido de la Región, una de sus prioridades es combatir la inseguridad, provocada principalmente por los robos de cebúes.

Es necesario subrayar que el dina regional de la Haute Matsiatra se promueve con el apoyo económico de la Unión Europea en el marco de un programa llamado ACCORDS (Programme d'Appui aux Communes et organisations rurales pour le Développement du Sud), que para el caso de Madagascar ha significado una insuflación económica desde el año 2004 para que el gobierno malgache pudiera acelerar el proceso de descentralización de las Comunas rurales del sur del país ${ }^{2}$.

Apuntábamos que una de las finalidades principales del dina regional es combatir la inseguridad en las zonas rurales de la Región, por este motivo, los robos de cebúes se han convertido en su caballo de batalla.

En el texto del dina regional de la Haute Matsiatra se dedica el capítulo segundo a los cebúes. En los 25 artículos que comprenden este capítulo se establecen las reglas, en primer lugar, referentes a la documentación necesaria de los animales y a los lugares de pasto y albergue de los mismos. De esta forma, en el artículo 11 se manifiesta que con el objetivo de disminuir los robos de cebúes debe reforzarse la ley de la siguiente forma: "Disponer de un registro de cebúes en cada fokontany", tener bien acondicionados los espacios donde se guardan los animales, velar por la protección de las personas fijando un lugar para los mercados de cebúes y los camiones para transportarlos".

${ }^{2}$ El programa ACCORDS finalizó el 30 de noviembre de 2010 presentando resultados desiguales en las distintas comunas que participaban en él. Los responsables de dicho programa en Madagascar resaltaron que la crisis económica y política que vivió el país en el año 2009, culminando con un golpe de Estado por parte de los militares, incidió particularmente a que los resultados no fueran los deseados en un principio, a pesar de ciertos avances constatados en el terreno (L'Express de Madagascar, 15 de diciembre de 2010).

${ }^{3}$ Organización político-territorial de creación estatal que aglutina en su seno un grupo de comunidades, generalmente entre 10 y 15 . 
En relación con la persecución de los ladrones y la forma de aviso de robo, los artículos de referencia son los que conforman el título II, en especial el articulo 13, el cual establece que cuando se produce un robo aquellos hombres válidos que tengan una edad comprendida entre los 18 y los 50 años deben seguir las huellas de los animales. Se advierte de que no puede detenerse la búsqueda para volver al fokontany hasta que no se encuentran los animales robados o bien se les pierde la pista definitivamente. Además, la mitad de los hombres debe quedarse en el fokontany para vigilar. Por otra parte, el artículo 16 dispone sobre la obligación de cada pueblo o fokontany que recibe un aviso de robo, el cual está obligado a "acudir inmediatamente a la persecución para ayudar, además debe transmitir el aviso a los otros pueblos para empezar lo antes posible la persecución de los ladrones. Igualmente quien disponga de armas debe llevarlas consigo".

Por lo que se refiere al procedimiento a seguir para redactar el informe de los hechos, en el artículo 20 del dina regional se establece que según lo que dispone la ley 2001-004, las autoridades locales tienen la obligación de redactar un informe de los robos y las persecuciones dentro de las 48 horas posteriores a los hechos. En caso contrario el fokontany deberá pagar una multa. La responsabilidad de las informaciones que se hacen constar en dicho informe se comparte entre el fokontany, la Comuna, el Distrito, la Región y el tribunal.

En la relación de multas que consta al final del texto del dina regional únicamente se hace referencia a los desacatos a la ley relativos a la vigilancia de las comunidades y la comunicación de los robos a las autoridades superiores. A pesar de que se tipifica minuciosamente el procedimiento de persecución de los ladrones, con el fin último de que éstos sean librados a las autoridades policiales, ninguno de los artículos se refiere al procedimiento a seguir para resolver el conflicto. Ello es debido a la prohibición de regular estos casos en el ámbito local de las comunidades. Tampoco hay constancia de multas para su aplicación. Esto significa que la costumbre jurídica simplemente desaparece, desde la perspectiva del derecho constitucional, como recurso para la resolución de los robos de cebúes.

Con el fin de aplicar una regulación estricta y secundada por la ley a este tipo de conflicto, el dina regional se empara en otros textos de ley que le secundan en su propósito.

El primero de ellos al que debemos referirnos es la ordenanza 60-106 sobre la represión de los robos de cebúes (Ordenanza 60-106 del 27 de septiembre de 1960 modificada y completada por la ley 61-030 del 18 de octubre de 1961, Journal Oficiel $n^{\circ} 190$ del 21 de octubre de 1961, p. 1818). En esta ordenanza los robos de cebúes se califican de crimen y se establece que deben sancionarse con la pena de muerte o los trabajos forzados, a perpetuidad o temporales. En dicha ordenanza se distingue, de una parte, el crimen de robo simple para el que se pueden aplicar penas de 5 a 20 años de trabajos forzados. De otra parte, el robo con agravantes, que debe ser juzgado por un tribunal criminal especial creado para tal efecto, $\mathrm{y}$ es condenado con la pena de muerte o trabajos forzados a perpetuidad. En el articulo 4 de la ordenanza 60-106 se dispone que: "Será de aplicación la pena de muerte para aquellas personas que sustraigan o intenten sustraer de forma fraudulenta uno o más cebúes y 
si dicha infracción viene precedida, acompañada o seguida de un asesinato". Por su parte, en el artículo 5 de la ordenanza 60-106 se especifica que a toda persona que se declare culpable de sustraer fraudulentamente uno o más cebúes se le condenará a trabajos forzados a perpetuidad si el robo se ha cometido con al menos tres de las siguientes circunstancias agravantes: "La nocturnidad, la reunión de dos o más personas, el porte de un arma (visible u oculta), con violencia o alegando una falsa orden de la autoridad civil o militar". Finalmente, en el artículo 6 se precisa que: "Todo otro robo de uno o más cebúes, cometido en los campos, pasturas, parques o cualquier otro lugar será penado entre 5 y 20 años de trabajos forzados".

Respecto a lo que se pronuncia en la ordenanza 60-106 hay que tener en cuenta dos cuestiones fundamentales: En primer lugar, oficialmente, la pena de muerte no se aplica en Madagascar desde el año 1958, fecha en que tuvo lugar la última condena de este tipo. Actualmente las sentencias que conllevan la pena de muerte son conmutadas por penas de prisión. En segundo lugar, y como consecuencia de lo primero, los robos de cebúes en su casi totalidad terminan siendo penados con un máximo de 10 años de prisión, debido normalmente a la falta de pruebas incriminatorias (Rakoto, 2010).

El segundo texto al que debemos remitirnos es el decreto 13/REG/HM del 13 de agosto de 2005 sobre la organización de la autodefensa local y la participación activa de las comunidades en la persecución de los robos de cebúes. En este texto se dispone el procedimiento que deben seguir las comunidades rurales de la Región para alertar a las autoridades correspondientes sobre un robo que se esté perpetrando.

Concretamente en el artículo 6 del decreto se establece que toda persona que tenga conocimiento de un robo de cebúes debe dar aviso al fokontany que, a su vez, debe informar a la policía o al servicio de la gendarmería más cercano. Al mismo tiempo deben organizarse todas las disposiciones necesarias para seguir las huellas y recoger las informaciones del robo y de la organización de la persecución. Además se precisa que: "Dos miembros del fokontany, entre los cuales el presidente, asistirán a la posterior audición del sospechoso que realizará un oficial de la policía". Igualmente, en el mismo artículo 6 también se dispone como deberán proceder los miembros de dichas comunidades para llevar a cabo la persecución de los ladrones y su posterior entrega a las autoridades policiales. Además de la obligatoriedad de participar en la persecución para todo hombre válido debe tenerse en cuenta que ésta se organizará de la siguiente forma: "Un primer equipo llamado "voromahery" empezará la persecución, un segundo equipo llamado "tohana" procederá a formalizar las pesquisas y a recoger víveres antes de encontrarse con el primer equipo para reforzarlo, un tercer equipo llamado "manda" velará por la seguridad del pueblo". El equipo de persecución proveído de un pasaporte de persecución, que debe librar el fokontany, puede entrar en todas las propiedades que se crea necesario. Aunque estos textos de ley sirvan de apoyo para regular los robos de cebúes en la Región, en el ámbito local de las comunidades las reglas del dina regional deben aplicarse en primera instancia, sin que ello exima de un posterior juicio en un tribunal estatal. La primera de las reglas que se debe cumplir es la redacción del informe sobre el 
robo acontecido, que debe elaborar el presidente del fokontany para entregarlo a las autoridades de la Comuna. En dicho informe deben constar: las pruebas del robo, la demostración de que realmente se ha producido el robo, los testigos, la forma de acceso a los animales y la forma de detención de los ladrones (Artículos 32-35 del dina regional de la Haute Matsiatra).

Estas son las disposiciones de la ley constitucional para la regulación de los robos de cebúes en la Región de la Haute Matsiatra. Sin embargo, si nos apartamos momentáneamente de las formas legales abstractas y tomamos los casos de conflicto que tienen lugar a causa de los robos de cebúes en las comunidades rurales de la Región, nos encontramos de frente con la aplicación real de estas leyes.

Para esclarecer de qué forma se desarrolla la aplicación de las leyes constitucionales en el marco local de las comunidades, así como las interrelaciones que tienen lugar con la costumbre jurídica, daremos cuenta de una descripción de las distintas etapas que se suceden a partir de un robo de cebúes. Para ello es necesario que partamos de una constatación: Cuando las comunidades derivan un conflicto al tribunal estatal, de acuerdo con lo que establecen las reglas del dina regional, no comprenden que se aplica justicia sino que se cumple con la ley (Rosés, 2013). Por ello, la costumbre jurídica aparece como un recurso en el que empararse con frecuencia, que sale a luz en diferentes momentos del procedimiento.

Cuando acontece un robo de cebúes, decíamos anteriormente, la primera disposición legal que deben atender las comunidades hace referencia a la persecución de los ladrones. Lo primero que debe ponerse en marcha es la alerta. El fokontany o la comunidad que sufre el robo y se percata de ello debe difundir el aviso de acuerdo con lo dispuesto en el decreto 13/REG/HM.

En este proceder identificamos distintos elementos que provienen de la costumbre jurídica local. La forma de dar el aviso, emitiendo de manera cadenciosa el sonido "cu-cu", se remonta en el tiempo cuando las comunidades se avisaban de esta manera sobre la presencia de ladrones. Del mismo modo, la organización de los distintos grupos de hombres válidos para llevar a cabo la persecución de los ladrones y la vigilancia de la comunidad, de acuerdo con lo que establece el decreto 13/ REG/HM, encuentra sus orígenes en formas de la costumbre jurídica. No obstante, la manera de llevar a cabo la persecución incluye preceptos de nueva creación, por ejemplo la obligación de perseguir a los ladrones hasta dar con ellos. La costumbre jurídica, por su parte, establece que la persecución puede terminar si el grupo de perseguidores considera que se encuentra en peligro, algo que ocurre habitualmente puesto que persiguen a ladrones con armas de fuego de gran calibre.

Llegado el punto en que haya sido posible alcanzar a los ladrones, el presidente del fokontany robado debe apresurarse a redactar un informe de los hechos cumpliendo con la ley. Dado que en caso de no redactarlo el fokontany debe pagar una multa, la redacción del informe es la disposición legal más cumplida en el ámbito local. Los responsables políticos de los fokontany, que no dejan de ser unos vecinos más, han aprendido qué indicaciones legales deben asumir en caso de robo de cebúes de manera ineludible. No obstante, obedecer la ley, el dina regional, a menudo conlleva otros problemas para los miembros de las comunidades. Denunciar a los 
ladrones, de acuerdo con lo que dicta la ley, se traduce frecuentemente en amenazas, nuevos robos o hasta la muerte. Pero la ley es severa y las multas, en caso de incumplirla, elevadas.

La siguiente etapa que prevé el dina regional hace referencia a la entrega de los ladrones a las autoridades policiales para que sean juzgados en un tribunal estatal. De esta forma, el cometido de las comunidades se reduce a llevar a cabo la persecución de los ladrones de la forma en que se establece en el decreto 13/REG/HM, a pesar de la peligrosidad que entraña dicha práctica, y por otra parte la redacción del informe.

Como ya hemos mencionado en un principio, la aplicación de la costumbre jurídica queda terminantemente prohibida para estos casos. A pesar de ello, en el ámbito local se aplican los procedimientos jurídicos propios de la costumbre jurídica para aquellos casos de robo que cometen individuos que pertenecen al mismo fokontany. Aunque el fokontany sea una organización político-territorial de creación estatal y se trate de un organismo administrativo, las comunidades que en ellos se congregan acostumbran a compartir una historia y unos vínculos de parentesco o de alianza. Esto significa que las relaciones entre sus miembros facilitan la conveniencia de todos en aplicar la costumbre jurídica para los casos de robos de cebúes acontecidos entre miembros de un mismo fokontany, a pesar de que este proceder sea ilegal. De este modo, los dina locales se mantienen como un paliativo a la incapacidad de los dina estatales, aunque el Estado los procure eliminar con la creación de los dina regionales (Rosés, 2013).

Es por ello que cuando los robos se suceden entre miembros de un mismo fokontany la situación cambia radicalmente. Cada caso, tratado de manera particular, será juzgado por la comunidad aplicando los principios de la costumbre jurídica. $\mathrm{Y}$ en este juicio, ilegal, se emitirá la pena que se le impone. Para aquellos casos que irremediablemente deban derivarse al tribunal estatal, el inculpado pagará, en primer lugar, la multa que le impone el dina regional. Una vez celebrado el juicio y cumplida la pena dictada por el tribunal estatal, a su vuelta a la comunidad deberá cerrarse el conflicto en el ámbito local mediante la aplicación de la costumbre. Porque ajustadas las cuentas con el Estado, el proceso no se da por concluido hasta que la comunidad lo juzga localmente. Aunque el inculpado ya haya sido juzgado por un tribunal estatal y haya cumplido con su pena.

De esta forma, quebrantando la ley, se procederá a dar voz a los implicados en el robo - el ladrón o ladrones y la persona o personas robadas - para que mediante la aplicación de los procedimientos de resolución propios de la costumbre, las partes lleguen a un acuerdo, hagan las paces y se resuelva el conflicto.

Debe tenerse en cuenta que la aplicación de la costumbre no significa penas laxas para los inculpados, más bien todo lo contrario. En primer lugar, el mero hecho de someterse a juicio ante toda la comunidad se considera una situación deshonrosa para aquel que ha robado, así como para sus familiares. De otra parte, el perdón que pide a la persona que ha robado debe ser sincero y la paz debe sellarse con el firme propósito de volver a la anterior situación de harmonía entre miembros de una misma comunidad of fokontany. Comprendiéndose que se ha faltado al compromiso 
con los ancestros y los miembros vivos de la comunidad es necesario dar ejemplo en este tipo de juicios.

Cuando la persona que ha cometido el robo lo ha hecho por primera vez y se muestra arrepentida, por ejemplo si ha robado sin emplear la violencia o si sus circunstancias económicas lo han empujado a robar a la desesperada, la sentencia girará alrededor de dos posibles opciones: La realización de trabajos para la comunidad o el fokontany durante un tiempo determinado, con el fin de mostrar públicamente su arrepentimiento y el deseo de responsabilizarse de su acción. O bien, la realización de trabajos puntuales en los campos de cultivo de la persona a la que ha robado, acción que le permitirá resarcir su acto delictivo. Esto significa que el procedimiento se desarrollará del mismo modo en que se sucedería si se tratara de cualquier otro tipo de conflicto local, es decir, con el propósito firme de llegar a la conciliación de las partes en conflicto.

No obstante, si la persona juzgada es reincidente nos encontramos ante un caso más controvertido puesto que la pena que debe imponérsele es la de la exclusión de la comunidad. Esta exclusión puede revestir diferentes formas según el caso. Asimismo dependerá de si el ladrón se retracta de lo cometido y admite su responsabilidad. Siendo así, puede tratarse de una exclusión temporal, lo cual puede significar, por ejemplo, que ningún miembro de la comunidad pueda casarse con los parientes del ladrón o bien no permitir al inculpado que participe en las actividades comunes. En muchas ocasiones la familia del inculpado se ve involucrada en la sentencia puesto que se apela a una responsabilidad compartida. Pero es posible que en estos casos el ladrón pueda eludir ser expulsado de la comunidad. En otros casos no quedará otra opción que expulsarlo de la comunidad, por ejemplo si ha empleado la violencia con sus convecinos o ha facilitado el acceso a ladrones que no pertenecen a la comunidad o fokontany atacado. Además, en estas circunstancias, deberá derivarse el conflicto al tribunal estatal. La pretensión no será que allí se resuelva el conflicto sino que al tratarse de un caso en el que la costumbre ya no puede actuar, dado que el inculpado demuestra no respetar los principios que guían esta costumbre, su demanda de perdón no es creíble ni válida.

En último término encontramos la llamada gran exclusión. Se trata de la pena más severa y la mayor vergüenza, que es la prohibición de ser enterrado en la tumba de los antepasados. Esta sanción será aplicada para aquellos ladrones que con su robo hayan llevado una violencia extrema a la comunidad y como consecuencia de ello se hayan producido muertes o daños irreparables.

\section{Reflexiones finales}

Como hemos apuntado en distintos momentos, las reglas y procedimientos de la ley constitucional y aquellos de la costumbre jurídica no se aplican de forma exclusiva. Ambos procedimientos, y por lo tanto ambos derechos, se articulan y entran en conflicto cuando las comunidades se encuentran ante un caso de robo de cebúes que debe resolverse. Aunque cabe la posibilidad de que se apliquen de manera unilateral, y de hecho así ocurre en ocasiones, la interrelación de principios y reglas de uno y otro derecho es lo más frecuente. 
Es probable que ambas resoluciones - del tribunal estatal y de la comunidadsean contradictorias, o simplemente distintas, pero en todo caso en el ámbito local prevalecerá la emitida por la comunidad puesto que la costumbre prevé resoluciones que se adecuan más satisfactoriamente a las necesidades locales. Cuando la pena impuesta por la comunidad esté saldada se dará por cerrado el caso.

En estas idas y venidas, de la comunidad al tribunal y viceversa, de las leyes estatales al dina regional y a la costumbre jurídica local, constatamos que no nos encontramos ante sistemas jurídicos que funcionan o se aplican independientemente sino que, al trasponer los principios jurídicos de unos y otros en el marco práctico y local de las comunidades, éstos se solapan, se omiten a partes, se cumplen a medias. Se viaja constantemente de la legalidad a la ilegalidad por el camino de la legitimidad (Rosés, 2013).

Y en este proceso de articulación entre culturas jurídicas tan distintas, el papel de las comunidades no debe dejarse de lado. Con sus prácticas jurídicas, constituyendo un nuevo procedimiento de resolución de conflictos, se aúnan, articulándose conflictivamente, los principios de uno y otro derecho. Ello da lugar a nuevas formas jurídicas que se adaptan, más o menos fluidamente, a un nuevo contexto. Es por ello que la etnografía debe remitirse al derecho y viceversa, para poder comprender estas nuevas dinámicas jurídicas que tienen lugar en el ámbito local de las comunidades rurales de Madagascar y ponen en relación el derecho y la etnografía.

\section{Referencias bibliográficas}

ASSIER-ANDRIEU, Louis.

2001 "Penser le temps culturel du droit: le destin anthropologique du concept coutume". L'Homme. Revue française d'anthropologie, 160: 67-90.

NJARA, Ernest.

1993 "Les dinan'ny fandriampahalemana ou chartes de la securité publique". Droits et Cultures, 26: 221-234.

RAKOTO, Ignace.

2011 "L'insécurité rurale liée au vol de boeufs: quelques propositions de solution". Taloha, 19, http://www.taloha.info/document.php?id=906.

RAKOTOARISOA, Claude.

2010 "Seule l'Union européenne décide de la suite du programme ACCORDS". L'Express de Madagascar, 15 de diciembre de 2010.

RAZANABAHINY, Victorine.

1995 Le dina. Convention entre membres de communautés villageoises. Son opportunité ou non Dans la conservation de la nature. Le cas de la réserve naturelle intégrale d'Andohahela, Tolagnaro. Tesis doctoral. Facultat de Historia. Université d'Antananarivo.

ROSÉS TUBAU, Mariona

2013 Responsabilitats adjudicades, compromisos heretats. Conflictes $i$ articulacions entre cultures i pràctiques jurídiques a la Regió de l'Haute Matsiatra de 
Madagascar. Tesis doctoral. Facultad de Filosofía, Geografía e Historia. Universitat de Barcelona.

TERRADAS SABORIT, Ignasi.

2008 Justicia Vindicatoria. Madrid: CSIC.

Decreto ${ }^{\circ} 13 /$ REG/HM del 31 de agosto de 2005 sobre la organización de la autodefensa local y la participación activa de las comunidades en la persecución de los robos de cebúes.

Dinan'ny Matsiatra Ambony, Gobierno de Madagascar, 2007.

Ley 2001-044 del 25 de octubre de 2001 sobre la reglamentación general de los dina en materia de seguridad pública, Journal Oficiel n²746 del 19 de noviembre de 2001, p.3047.

Ordenanza $\mathrm{n}^{\circ} 60-106$ del 27 de septiembre de 1960 modificada y completada por la ley $\mathrm{n}^{\circ} 61$ 030 del 18 de octubre de 1961 , Journal Oficiel $n^{\circ} 190$ del 21 de octubre de 1961, p.1818. 